\title{
THE EFFECTIVE PRICE IN STATE-SPONSORED LOTTERY GAMES: OPPORTUNITIES FOR MARKETING ACTIONS THAT SUPPORT REVENUE GENERATION FOR PUBLIC POLICY MAKING
}

\author{
Rodrigo Guesalaga, Pontificia Universidad Católica de Chile, Chile
}

Pablo Marshall, Pontificia Universidad Católica de Chile, Chile

\begin{abstract}
Lotteries are used in many countries to raise money for public policy making. Pricing strategies in this product category are unique, because although the game's nominal price is relevant for revenue earning, its effective price - which includes the expected value of a lottery ticket - determines purchasing decisions.

This research explores how to affect the effective price of lottery tickets and thus increase their demand. Specifically, the authors propose a model to estimate the probability of a jackpot rollover in lottery games under both random and conscious number selection. In addition, the authors present a demand model for lottery games, where the effective price is the main predictor. Finally, they discuss how marketing actions can affect the effective price and, consequently, the demand for lottery tickets. The data is provided by Polla Chilena de Beneficencia, a mayor player in the lottery games industry in Chile.
\end{abstract}

References available upon request 